\title{
Dorothea Wendebourg
}

\section{Essen zum Gedächtnis}

\author{
Der Gedächtnisbefehl in den Abendmahlstheologien der Reformation
}

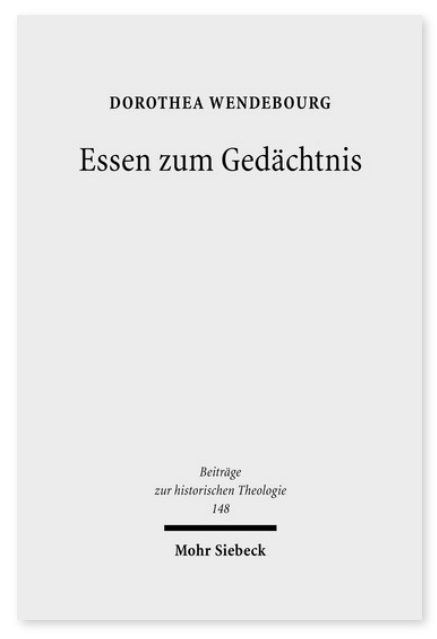

2009. VIII, 268 Seiten. BHTh 148

ISBN 978-3-16-151058-8

DOI 10.1628/978-3-16-151058-8

eBook PDF 104,00€

ISBN 978-3-16-149970-8

Leinen $104,00 €$
Nach dem Neuen Testament ist das Abendmahl »zu Christi Gedächtnis« gestiftet. Was mit dieser Bestimmung gemeint ist, gehört zu den zentralen abendmahlstheologischen Problemen nicht nur der biblischen Exegese und der systematischen Theologie, sondern auch der Liturgiewissenschaft und des ökumenischen Dialogs. In letzterem Zusammenhang gewann das Gedächtnismotiv besondere Prominenz, weil es häufig als Brücke zur Überwindung der Meßopferkontroverse betrachtet und behauptet wurde, diese Kontroverse wäre bei richtiger Einschätzung des »Gedächtnisses« schon im 16. Jahrhundert überflüssig gewesen. Allerdings hat es bislang keine Untersuchung gegeben, die der Frage nachgegangen wäre, wie das Gedächtnismotiv auf reformatorischer Seite damals tatsächlich verstanden wurde. Nach zwei Hintergrundkapiteln über das Spätmittelalter und Erasmus von Rotterdam erörtert Dorothea Wendebourg jene Frage für die Hauptreformatoren der ersten Generation, Martin Luther, Andreas Karlstadt, Huldrych Zwingli, Johannes Oekolampad und Philipp Melanchthon. Charakteristisch ist für diese Theologen, daß sie den Vollzug, der »zu Christi Gedächtnis« geschieht, im von Christus eingesetzten Essen sehen, woraus sich, insbesondere bei Luther, die Frage ergibt, was es bedeutet, daß »Christi Gedächtnis« gerade in dieser Weise gehalten werden soll. Innerhalb des gemeinsamen Rahmens differiert die nähere Bestimmung des Gedächtnismotivs beträchtlich, so daß es nicht nur in unterschiedlicher Weise gegen das Meßopfer ins Feld geführt wird, sondern, in eigentümlicher Verschränkung mit dieser Kontroverse, auch eine Schlüsselrolle in den Auseinandersetzungen unter den Reformatoren spielt. Nicht zuletzt schlagen sich diese Differenzen auch liturgisch nieder.

Dorothea Wendebourg Geboren 1952; Professor emeritus für Kirchengeschichte an der Theologischen Fakultät der Humboldt-Universität zu Berlin.

Jetzt bestellen:

https://mohrsiebeck.com/buch/essen-zum-gedaechtnis-9783161510588?no_cache=1

order@mohrsiebeck.com

Telefon: +49 (0)7071-923-17

Telefax: $+49(0) 7071-51104$ 